\title{
Weightlessness and skeleton homeostasis
}

\author{
Konstantinos Ziambaras ${ }^{1}$, Roberto Civitelli ${ }^{2}$, Stathis S. Papavasiliou ${ }^{1}$ \\ ${ }^{1}$ Department of Endocrinology, University of Crete Medical School, Iraklion, Grete, Greece, ${ }^{2}$ Division of Bone \\ and Mineral Diseases, Washington University School of Medicine, St Louis MO, USA
}

\begin{abstract}
As human beings venture into space in the $21^{\text {st }}$ century, they will be confronted with a "hypodynamic" and thus hostile environment for the bone homeostasis, that could potentially compromise their mobility in general and skeletal strength in particular after landing. From this point of view, space flight studies are especially interesting and intriguing models for scientists. Space studies, however, must not only overcome enormous technical problems but are also limited in size and frequency. Therefore, ground-based models have also been developed to evaluate the effects of skeletal unloading. The most popular model for human studies is prolonged bed rest with normal volunteers, although studies with paraplegics have also been undertaken. In animals, the hindlimb elevation (tail suspension) model simulates space flight models and is well tolerated by the animals with minimal evidence of stress. Although negative calcium balance and bone loss have been observed in all the aforementioned models of skeletal unloading, the exact mechanism(s) by which this occurs are still unknown and mainly speculative.
\end{abstract}

Keywords: Weightlessness, Osteoporosis, Space flights, Calcium homeostasis

\section{INTRODUCTION}

The skeletal structures of vertebrate organisms are constantly subjected to various mechanical stresses (including gravity). The mobility of vertebrates depends on the successful adaptation of the musculoskeletal systems to these stresses. The importance of physical activity in maintaining adult bone mass is widely recognized, and weight-bearing

Address correspondence and requests for reprints to: Konstantinos Ziambaras, MD, PhD, Arch. Makariou \& Melissinon Street, GR-71305 Iraklion Greece,

Tel./Fax: +30-2810-282-678, e-mail: ziambaras@yahoo.gr

Received 07-09-04, Revised 10-11-04, Accepted 20-11-04 exercise has been advocated for the treatment of osteoporosis.

To better comprehend the effect of mechanical factor(s) on human biology in general and skeletal economy in particular, study of the conditions where these factor(s) are absent would probably contribute significantly to such understanding. The results from these studies, however, are not uniform, since the conditions under which they have been undertaken are variable. Therefore, one should be very cautious when extrapolating results from animal studies to humans and from space flight studies to ground-based conditions. ${ }^{1,2}$ Nevertheless, some patterns emerge. 


\section{A. SKELETON HOMEOSTASIS DURING SPACE FLIGHT}

\section{Human studies}

Much of our information concerning the impact of space flight on bone mineral homeostasis shows marked individual variation. This is due to the small number of crewmembers studied and the differences between flights with regard to duration, diet applied, use of physical exercise and pharmacological countermeasures. ${ }^{3,4}$ Therefore, conclusions should be drawn with caution. ${ }^{5}$

The first indication of the negative influence that microgravity exerts on bone homeostasis was the increased urinary calcium excretion during the Vostok 2 and 3 space flights in the ' 60 s. $^{6}$ This observation was followed by measurements of bone density from the calcaneus during the Gemini IV, V, VII space missions (4, 8 and 14 days duration, respectively). ${ }^{7}$ All measurements yielded bone loss in the range of 2.9 to $15 \%$. Paradoxically, smaller loss was incurred during the 14-day flight (longest duration)! This was attributed to the isotonic muscle-strengthening program that the astronauts followed during this particular flight. Studies during the space flight Soyuz-9 verified the previous observations. ${ }^{8}$ In space flight Apollo-8 cosmonauts showed increased gastrointestinal calcium losses along with increased urinary calcium excretion. ${ }^{9}$ This was the first indication of a profound effect of weightlessness condition on gastrointestinal calcium absorption. Recently, fractional calcium absorption was determined by use of the stable strontium test in one cosmonaut who spent 20 days in space and was kept on a constant diet regarding calcium and vitamin D intake. In agreement with earlier observations, intestinal calcium absorption was markedly reduced during the flight as compared with the pre- and post-flight period. $^{10}$

In the early '70s, during the three Skylab flights, bone mineral measurements revealed loss of bone density from the calcaneus to be greater in the 84day flight than in the shorter flights (up to $8 \%$ ). ${ }^{11-13}$ Similar results were obtained in the Salyut- 6 cosmonauts (bone losses up to 19\%). Again, greater losses were observed in the 140 to 184-day flights than in the 75 -day flight. ${ }^{14}$ On the other hand, bone density changes in non-weight bearing bones, such as the radius and ulna in the Skylab astronauts, were minimal even after 84 days. ${ }^{15-17}$ Interestingly, little recovery and even further loss of bone density (at least in the heel) occurred after landing. ${ }^{18}$

In conclusion, weight-bearing bones are likely to be the bones most affected by weightlessness. ${ }^{19}$ The loss in bone mineral from such bones may be progressive, at least over 6 months, with a slow recovery, which may not reach the pre-flight levels even 5 years after landing. ${ }^{5}$ However, it appears that exercise regimens employed by cosmonauts during the three Skylab missions were, at least partially successful in preventing bone loss. ${ }^{16,20}$

Microgravity induces an uncoupling of bone remodeling between formation and resorption that could account for the bone loss. ${ }^{21}$ In fact, bone resorption markers, such as N-telopeptide (N-Tx), Ctelopeptide (C-Tx) pyridinolines (PYR) and D-pyridinolines (D-PYR), increase very early after the flight and return to normal pre-flight level within 13 weeks after landing. ${ }^{10,21-23}$ Although not a consistent finding during space flights, ${ }^{10,24}$ a fall in the parathyroid hormone (PTH) and 1,25-dihydroxy-vitamin-D $\left(1,25(\mathrm{OH})_{2} \mathrm{D}\right)$ levels during the 8-day Spacelab-2 mission flight was found. ${ }^{10,25}$ PTH levels remained low, whereas serum calcium levels rose during flight with recovery afterwards..$^{24,25}$ The above changes point to an increased efflux of calcium from bone to the circulation as a primary event due to weightlessness, which subsequently suppresses PTH and vitamin D circulating levels (see also section $\mathrm{B}$ ). The low PTH levels and the fall in $1,25(\mathrm{OH})_{2} \mathrm{D}$ levels could result in the decreased intestinal calcium absorption and increased renal calcium excretion observed during the space missions. ${ }^{6,910,22,26,27}$ It seems likely that matrix/cell interactions, including systemic hormones (PTH. GH, 1,25(OH) 2 D), locally produced factors (IGF-1, BMPs, PTHrP, TGF beta) and adhesion molecules such as the integrins, must underlie many of these phenomena. ${ }^{28}$

\section{Animal studies}

The above results are in agreement with the results from animal (mainly rat) flight studies. As with human studies, some caution is needed in the interpretation of these results because differences in ex- 
perimental conditions, such as animal age, sex, body weight, pregnancy and variable delay (from hours to days) in post flight sample collection (i.e. sacrifice of the animals), cloud the interpretation of the data. When these variables are taken into account, the skeletal response is observed to vary with respect to weight bearing, its anatomic location and the presence of muscular insertions into cortical areas.

The best documented change in bone during space flight in growing rats is a remarkable reduction of periosteal bone formation and longitudinal bone growth. This is evidenced by the appearance of an extensive arrest line in the periosteum of cortical bone and decrease in primary spongiosa width. ${ }^{29-32}$ Two tetracycline labels given to young rats 3 days before and 3 days after a 19.5-day period flight were nearly superimposed in histomorphometric measurements of tibial bone, indicating a reduction in bone formation and peripheral bone growth ${ }^{31}$. Interestingly, the bone formation rate was not uniformly depressed in the cross section of the tibia and in fact was less severe at the level of the crest of the anterior tibia, where muscles are inserted. ${ }^{31,33}$ This raises the possibility that the deleterious effects of mechanical unloading in microgravity can be partially avoided by muscular contractions. ${ }^{34}$

Space flight leads to a decrease in osteoblast number and activity, ${ }^{35-37}$ which is likely the result of altered differentiation of osteoblast precursors. ${ }^{35,38,39}$ At least one aspect of the reduction of bone formation is the inhibition of osteoblast synthetic capacity. In fact, after the 1-week Spacelab 3 mission, tibial osteoblasts had a smaller cytoplasmic area, probably leading to reduced collagen secretion. ${ }^{36,39}$ It has been shown that osteoblast precursors in the periodontal ligament remained immature during the flight, ${ }^{38}$ a phenomenon which appears to be transient, since there is a rapid recovery mechanism for osteoblasts differentiation within few hours after the flight. ${ }^{40,41}$ In line with the above, the markers of bone formation, osteocalcin ${ }^{32,43,44}$ and alkaline phosphatase change in an opposite direction as a result of the inhibition of osteoblastic differentiation to more mature forms. It is known that the mRNA levels of alkaline phosphatase increase during the phase of formation and maturation of bone matrix, whereas osteocalcin mRNA levels increase (with concomitant decrease of mRNA alkaline phosphatase levels) at the beginning of bone matrix mineralization. ${ }^{42}$ Consequently, osteocalcin levels in serum and bone tissue decrease during space flight, whereas alkaline phosphatase levels increase during space flight (although decrease of osteoblastic alkaline phosphatase has also been reported on one occasion ${ }^{45}$ ). However, one should be cautious when comparing results among studies: for instance, serum osteocalcin is known to be age dependent in the rat. ${ }^{34,43}$

Osteoclast number and activity, on the other hand, remain unchanged in most studies of bones from space flight animals..$^{30,34,36,37}$ The only possible exceptions related to studies of less than one-week duration, where an increase in the osteoclastic population has been observed in different bone sites in pregnant rats. ${ }^{33,46}$ It could be advocated that although resorption activity could be transiently elevated between the $1^{\text {st }}$ and $2^{\text {nd }}$ week of microgravity exposure, for longer periods of weightlessness bone turnover decreases.

Associated with reduced bone mass, architectural changes that may contribute to the decrease in bone strength after landing are recognized. ${ }^{28,34}$ In weightbearing bones as tibial metaphyses, a decreased mass of trabecular bone ${ }^{47,48}$ and altered morphology of trabeculae ${ }^{47}$ has been reported during many space flights of relatively short duration (18.5-22 days). As early as the $7^{\text {th }}$ day of microgravity exposure, the number of trabeculae in the proximal metaphysis of the tibia of growing male rats are rapidly and markedly reduced ${ }^{28,34}$ and also become thinner, ${ }^{34}$ although the latter has not been confirmed by all studies. This leads to a reduction in trabecular density and increase in trabecular separation. ${ }^{34}$ Bone formation process is defective as is revealed by the reduced osteoid thickness and the bone surface that covers. ${ }^{34}$ The net result of these space flight-induced changes is weaker bone, ${ }^{29,49,50}$ which was partially prevented in animals maintained in the $1 g$ centrifuge.$^{51}$ After 2-3 weeks in space, the number of trabeculae is returned to normal but their thickness remains reduced. ${ }^{52}$ 


\section{B. HUMAN PROLONGED BED REST STUDIES}

Although not a perfect analog of space flight-induced bone atrophy, bed rest does unload the skeleton in a manner similar to weightlessness. Prolonged (up to one year!) complete bed rest in volunteers results in a very rapid uncoupling between bone formation and resorption, ${ }^{53}$ with fast bone loss. ${ }^{54,55}$ After a period of 4-8 months of complete bed rest, increased urine and fecal calcium excretion $^{53,55,56}$ and decreased intestinal calcium absorption occurs, ${ }^{53}$ resulting in a negative calcium balance. The estimated calcium loss rate is approximately $\sim 0.5 \%$ /month. Urine phosphorus excretion follows a similar pattern with calcium, albeit to a lesser degree. ${ }^{55,57,58}$ Bone resorption markers (pyridinolines, NTx and hydroxyproline) increase, ${ }^{53,56,59-61}$ whereas bone formation markers (osteocalcin and bone alkaline phosphatase) remain unchanged. ${ }^{56,62} \mathrm{~A}$ small decrease in $1,25(\mathrm{OH})_{2} \mathrm{D}^{53,56,59,63}$ and occasionally in $\mathrm{PTH}^{56,63}$ levels have also been found. These results are consistent with the view that calcium and phosphorus are mobilized from bone as a primary event and depress circulating levels of major calcium-regulating hormones (similar to space flight). These subjects lost bone most extensively from the calcaneous $(\sim 10 \%)$, with lesser losses from the femoral neck and spine ( 3-4\%). ${ }^{54,56}$ Reambulation is accompanied by reversal of all aforementioned biochemical changes. Reduction of bone resorption markers, ${ }^{56}$ increase of $\mathrm{PTH}^{56}$ and bone formation markers ${ }^{53,59}$ and, finally, normalization of intestinal calcium absorption, have all been demonstrated during this phase. However, only the calcaneous showed significant recovery of bone density during reambulation. ${ }^{54}$ Interestingly, an increase in bone density in the skull $(\sim 3 \%)$ was observed during the bed rest (see below). A similar 120-day study that included iliac crest bone biopsy samples showed little change in the trabecular bone volume of the iliac crest, ${ }^{56,65}$ although osteoclast numbers were increased. ${ }^{65}$ The rate of bone mineralization, ${ }^{56,65,66}$ the mineral apposition rate ${ }^{56,65}$ and the osteoid surface ${ }^{67}$ were decreased, pointing to a reduction in new bone formation due to skeletal unloading. In this study, some of the participants received etidronate, which blocked the rise of the osteoclasts without significant changes in the trabecular bone volume. A 360- day bed rest study, in which exercise as well as etidronate was evaluated, showed that etidronate was a more effective countermeasure than exercise in preventing the loss of bone mineral density in the femoral neck. ${ }^{68}$ A shorter 7-day bed rest study confirmed the reduction in bone formation and mineral apposition rates on bone biopsy specimens from the iliac crest and the increase in urinary pyridinoline crosslink excretion but also noted increased serum osteocalcin levels, which suggests a general increase in bone turnover. ${ }^{69}$

Similar to the space flight data, bed rest studies show the greatest losses in bone mineral from those bones that are subjected to greatest gravitational stress before bed rest. The observation that the skull increases in bone density may imply a redistribution rather net loss of bone mineral in these individuals. The bones in the head, which are not weight bearing, may act as an in vivo sink for the additional calcium and phosphorus mineral that are released from other skeletal sites during bed rest. ${ }^{55}$ This may also be a result of increased hydrostatic pressure in the head relative to the leg, due to the cephalad fluid shift during space flight and bed rest. ${ }^{54}$ Finally, another possibility is that the head experiences increased stress during bed rest from propping up to read or eat, thus stimulating bone remodeling.

Similar to the space flights, the above data suggest that the primary response of the skeleton to prolonged bed rest is an increase in bone resorption by osteoclasts with parallel release of calcium and phosphorus from bone tissue to the circulation. This results in suppression of calciotropic hormones, such as PTH and $1,25(\mathrm{OH})_{2} \mathrm{D}^{63}$

Interestingly, recent studies have shown a strong association between osteoclast recruitment, osteocyte apoptosis and the process of bone modelling or remodelling (i.e. repair of microdamages). ${ }^{70,71}$ If microdamage occurs in the cortical bone (i.e. by mechanical overloading), osteoclasts invade the cortical bone to remove the damage. This event is preceded by a marked osteocyte apoptosis at the affected area by several days. This sequence of events raises the possibility that the osteocyte apoptosis might actually represent the source of a signal for the osteoclastic invasion. The mechanism of initia- 
tion of apoptosis and the molecular signals between damage, apoptosis and osteoclast activity are under intense research

Bone density loss due to immobilization has also been described in neurological patients. ${ }^{63,72}$ Hemiplegic patients are a useful model because it offers the advantage of a proper control for the complex genetic and environmental cofactors involved in each individual. This is achieved by measuring changes in the bone mineral density in the paralyzed lower limb as compared to the nonparalyzed one. Although length of immobilization is a significant contributing factor to the bone loss (especially in men), it probably accounts for only a part of the total variance. ${ }^{73}$ Other factors, such as years since menopause in postmenopausal women, may play an even more important role as an independent determinant of bone loss than the length of immobilization itself. ${ }^{73}$ Notably, the initial phase of rapid bone loss follows a period of bone mass stabilization. ${ }^{66,74}$ It has been shown, for instance, that acute immobilization of adult humans as a result of spinal cord injuries resulted in a rapid loss of bone for approximately 25 weeks, after which time, trabecular bone volume stabilizes at roughly $67 \%$ of normal and appears to remain at this level indefinitely. ${ }^{66}$ In line with bone density changes, bone resorption markers increase dramatically (even up to ten time the normal), whereas the bone formation markers do not exceed the upper normal limits. ${ }^{75}$ The resulting osteopenia predisposes the bones to fracture even after minimal trauma, ${ }^{76}$ and indeed the frequency of osteoporotic fractures among this population is in the range of 5 to $20 \% .^{77}$

\section{RAT HINDLIMB ELEVATION MODEL (TAIL TRACTION METHOD)}

A model that uses hindlimb unloading of rats was developed to study the consequences of skeletal unloading and reloading as occurs during and following space flights. Studies using this model were initiated two decades ago and further developed at the National Aeronautics and Space Administration Research Center. In the hindlimb elevation (or tail traction) method, the tail of the animal is secured to an overhead pulley system by orthopedic tape.
The animals move around the cage using their forelimbs, while their hindquarters are elevated at approximately a $40^{\circ}$ angle from the floor of the cage. They are unable to rest their hindlimbs not even on the side of the cage and are thus non-weightbearing. Interestingly, the animals are subjected to minimal stress ${ }^{78}$ as indicated by the fact that the animals continue to gain weight, ${ }^{79-81}$ groom and show normal cortisol level and circadian rhythm. ${ }^{78,80,82}$ The forelimbs are normally weighted ${ }^{83}$ and can serve as internal controls, although we now appreciate that the bones in the forelimbs are not perfect surrogates for the bones in the hindlimbs. ${ }^{84,85}$ This model mimics a number of features of space flight experiments, by removing weight-bearing loads from the hindquarters and producing a cephalic fluid shift. Bone formation $^{86-88}$ and mineralization ${ }^{86,88,89}$ in the unloaded hindlimbs are inhibited, osteoblast number is decreased, ${ }^{86,90}$ osteoclast number remains unchanged, ${ }^{86,90}$ serum and skeletal osteocalcin level and skeletal alkaline phosphatase level fall within the first few days of hindlimb elevation ${ }^{87,90}$ and bone strength diminishes. ${ }^{91}$ Osteoblast or stromal cells from the bones of the unloaded limbs proliferate more slowly in vitro, ${ }^{90}$ which suggests that an antiproliferative signal from skeletal unloading causes a persistent change in cell function. However, these changes are transient. Bone formation in the unweighted tibiae and lumbar vertebrae of 6-week-old growing rats was inhibited by 5 days but recovered at a nearly normal rate by 2 weeks of continued unloading. ${ }^{79,86,88}$ Interestingly, the normally loaded bones (i.e., the humerus $^{79,88}$ and cervical vertebra ${ }^{88}$ ) were not affected by hindlimb elevation. Following the changes in bone formation, osteocalcin and $1,25(\mathrm{OH})_{2} \mathrm{D}$ levels in blood of young rats fall by days $2-5$ only to recover to control level by day $15 .{ }^{87,93}$ Although rate of bone formation recovers in the younger animals despite continued unloading, the bone lost during the initial week was not regained as long as unloading was continued. ${ }^{88}$ However, resumption of normal weightbearing results in accelerated bone formation until bone mass is restored to normal. ${ }^{17,93}$ In contrast, 6month-old rats showed a more gradual reduction in bone formation due to skeletal unloading compared to the young rats, which continued even after 5 weeks of continued unloading with no sign of recovery. ${ }^{1}$ 
Similarly to space flight experiments, one should be very cautious in extrapolating results from animal studies to humans. We should keep in mind that in the growing rats, bone formation exceeds bone resorption, which is in contrast to the substantially lower bone formation rates in older animals and the tightly coupled bone formation and resorption phase in humans.

Similar to space flight and bed rest studies, hindlimb elevation also leads to a dramatic fall $(\sim 63 \%)$ in the serum $1,25(\mathrm{OH})_{2} \mathrm{D}$ levels, reaching a nadir by 5-7 days, and a return toward control values during the second week of unloading..$^{82,86,92,93}$ With the resumption of normal weight-bearing, bone formation is accelerated until bone mass is restored to normal. ${ }^{93}$ PTH levels were found unchanged throughout the experiments. ${ }^{92}$ Although these data suggest a strong link between the skeletal response of bone to unloading and $1,25(\mathrm{OH})_{2} \mathrm{D}$ production, infusion of $1,25(\mathrm{OH})_{2} \mathrm{D}$ fails to prevent the changes in bone formation induced by skeletal unloading, which in turn indicates that the fall in $1,25(\mathrm{OH})_{2} \mathrm{D}$ is not solely responsible for the cessation of bone formation. ${ }^{86}$ Furthermore, the lack of effect of hindlimb elevation on bones like the humerus, mandible and cervical vertebrae, which are not unloaded by this procedure, suggests that the local factors rather than systemic effects dominate the response of bone to skeletal unloading. Local factors within the bone itself, such as the transforming growth factorb (TGF-b), bone morphogenic proteins, basic and acidic fibroblast growth factor, and IGF-I and -II are likely to play a major role in mediating this response.

\section{PRESENCE OF MECHANICAL FACTORS}

Weight-bearing exercises, such as walking, jogging, running or stair climbing, have been introduced as means for the prevention or treatment of osteoporosis. ${ }^{95}$ Weight-lifting athletes, tennis and squash players are some striking examples of the effect of skeletal loading in real life..$^{96-98}$

Three mechanisms for coupling the load on bone to changes in bone formation have received the most attention: streaming potentials, mechanical strain, and fluid shear stress. These mechanisms are not mutually exclusive. Streaming potential results when bone is flexed, causing movement of the ionic milieu bathing the cells. The charge displacement generates local electric fields, which can influence cell metabolism. Mechanical strain applied directly to the cell membrane activates stretch-activated ion channels and other membrane-associated proteins, such as integrins, which are linked to the cytoskeleton in a variety of cellular processes and structures including the nuclear matrix. Cyclic mechanical strain (stretch) also promotes gap junctional cell to cell communication in osteoblastic cells in a way similar to parathyroid hormone or prostaglandin $\mathrm{E}_{2}{ }^{99,100}$ Fluid shear stress is likely to combine these mechanisms such that the movement of intercellular fluid in the canaliculi surrounding osteocytic processes generated by the flexion of bone applies a force to the cell membrane.

\section{E. CONCLUSION}

In summary, the presence (or absence) of mechanical factors appears to play a predominant role in bone homeostasis. H. Frost has suggested that mechanical factors dominate the hormonal-biological factors in regulating bone physiology. ${ }^{101}$ Nonmechanical factors such as various hormones, dietary calcium, cytokines, etc, influence skeletal adaptation to the action of mechanical factors, but by no means replace them. Nature, however, is characterized by synthetic processes and it appears that hormonal and mechanical factors interact in a remarkable harmonic way to maintain durable and healthy bone. Skeletal unloading in general and space flight in particular provide scientists with an excellent opportunity that can be used to understand the mechanisms by which bone mineral homeostasis is maintained. This information and experience may lead to more effective treatments when bone becomes fragile due to reasons less exotic than space travel.

\section{BIBLIOGRAPHY}

1. Bikle DD, Halloran BP, Morey-Holton E, 1997 Space flight and the skeleton: Lessons for the Earthbound. The Endocrinologist 7: 10-22.

2. Hawkey A, 2003 The physical price of a ticket into space. J Br Interplanet Soc 56: 152-159. 
3. Heer M, Boerger A, Kamps N, Mika C, Korr C, Drummer C, 2000 Nutrient supply during recent European missions. Pflugers Arch 441: 8-14.

4. Fettmen NJ, 2000 Dietary instead of pharmacological management to counter the adverse effects of physiological adaptations to space flight. Pflugers Arch 441: 15-20.

5. LeBlanK A, Shakleford L, Schneider V, 1998 Future human bone research in space. Bone 22: 113-116.

6. David H, 1963 Russians discuss space radiation in conference. Missiles and Rockets 21: 34.

7. Mack PB, LaChance PA, Vose VP, Vogt FB, 1967 Bone demineralization of foot and hand on Gemini-Titan IV, V, and VII astronauts during orbital flight. Am J Roentgenol 100: 503-511.

8. Birykov N, Krasnyhk IG, 1970 Changes in optical density of bone tissue and calcium metabolism in the cosmonauts Nikolayev AG, Sevastyanov VI. Kosmicheskaya Biologiya i Meditsina 4: 42-45.

9. Rambaut PC, Leach CS, Johnson PC, 1975 Calcium and phosphorus changes of the Apollo 17 crewmembers. Nutr Metab 182: 62-69.

10. Zittermann A, Heer M, Caillot-Augusso A, et al, 2000 Microgravity inhibits intestinal calcium absorption as shown by a stable strontium test. Eur J Clin Invest 30: 1036-1043.

11. Whedon GD, Lutwak L, Reid J, 1974 Mineral and nitrogen metabolic studies on Skylab orbital space flight. Trans Ass Am Phys 87: 95-110.

12. Rambaut PC, Johnson RS, 1979 Prolonged weightlessness and calcium loss in man. Acta Astronautica 6: 1313-1322.

13. Rambaut PC, Leach CS, Whedon GD, 1979 A study of metabolic balance in crewmembers of Skylab IV. Acta Astronautica 6: 1313-1322.

14. Stupakov GP, Kazeykin VS, Kozlovskiy A, Korolev VV, 1984 Evaluation of changes in human axial skeletal bone structures during long-term spaceflights. Space Biol Med 18: 42-47.

15. Uebelhart CD, Vico L, Moro L, Hartmann D, Roth M, Alexandre C, 1997 Effects of 1- and 6-month spaceflight on bone mass and biochemistry in two humans. Bone 20: 547-551.

16. Smith MC, Rambaut PC, Vogel JM, Whittle MW, 1977 Bone mineral measurement-experiment M708. In: Johnston RS, Dietlein LF, (eds) Biomedical results from Skylab. Scientific and technical information office. Washington D.C. NASA (SP-377); pp, 183-190.

17. Organov VS, Rahkmanov AS, Novikov VE, 1991 The state of human bone tissue during space flight. Acta Astron 23: 129-133.

18. Tilton FE, Degioanni JJC, Schneider VS, 1980 Longterm follow-up of Skylab bone demineralization. Aviat Space Environ Med 51: 1209-1213.

19. Grigoriev AI, Oganov VS, Bakulin AV, et al, 1998 Clinical and physiological evaluation of bone changes among astronauts after long term space flights. Aviakosm Ekolog Med 32: 21-25.

20. Thornton WE, Rummel JA, 1977 Muscular deconditioning and its prevention in space flight. In: Johnston RS, Dietlein LF, editors. Biomedical results from Skylab. Washington, D.C. NASA (SP-377); p, 191.

21. Caillo-Augusseau A, Lafage-Proust MH, Soler C, Pernod J, Dubois F, Alexandre C, 1998 Bone formation and resorption biological markers in cosmonauts during and after a 180-day space flight (Euromir 95). Clin Chem 44: 78-85.

22. Smith SM, Wastney ME, Morukov BV, et al, 1999 Calcium metabolism before, during, and after a 3-mo spaceflight: kinetic and biochemical changes. Am J Physiol 277: 1-10.

23. Smith SM, Nillen JL, Leblanc AD, et al, 1998 Collagen cross-link excretion during space flight and bed rest. J Clin Endocrinol Metab 83: 3584-3591.

24. Leach CS, Rambaut PC, 1977 Biochemical responses on the Skylab crewmen: an overview in biomedical results from Skylab. NASA Tech Bull 377: 204-216.

25. Morey-Holton ER, Schnoes HK, DeLuca HF, et al, 1988 Vitamin D metabolites and bioactive parathyroid hormone levels during Spacelab 2. Aerospace Med Assoc 59: 1038-1041.

26. Doty SE, Seagrave RC, 2000 Human water, sodium, and calcium regulation during space flight and exercise. Acta Astronaut 46: 591-604.

27. Holik MF, 1998 Perspective on the impact of weightlessness on calcium and bone metabolism. Bone 22: 105-111.

28. Bikle DD, Sakata T, Halloran BP, 2003 The impact of skeletal unloading on bone formation. Gravit Space Biol Bull 16: 45-54.

29. Vailas AC, Zernicke RF, Grindeland RE, et al, 1990 Effects of spaceflight on rat humerus geometry, biomechanics, and biochemistry. FASEB J 4: 47-54.

30. Wronski TJ, Morey ER, 1983 Effects of spaceflight on periosteal bone formation in rats. Am J Physiol 244: 305-309.

31. Morey ER, Baylink DJ, 1978 Inhibition of bone formation during space flight. Science 201: 1138-1141.

32. Backup P, Westerlind K, Harris J, Spelsberg T, Kline B, Turner R, 1994 Spaceflight results in reduced mRNA levels for tissue-specific proteins in the musculoskeletal system. Am J Physiol 266: 567-573.

33. Vico L, Alexandre C, 1992 Microgravity and bone adaptation at the tissue level. J Bone Miner Res 7: 445447.

34. Vico L, Chappard D, Palle S, Bakulin V, Novikov VE, Alexandre C, 1988 Trabecular bone remodeling after seven days of weightlessness exposure (BIOCOSMOS 1667). Am J Physiol 255: 243-247.

35. Zerath E, Holy X, Roberts SG, et al, 2000 Spaceflight inhibits bone formation independent of corticosteroid status in growing rats. J Bone Miner Res 15: 1310-1320. 
36. Turner RT, Evans GL, Wakley GK, 1995 Spaceflight results in depressed cancellous bone formation in rat humeri. Aviat Space Environ Med 66: 770-774.

37. Jee WSS, Wronski TJ, Morey ER, Kimmel DB, 1983 Effects of spaceflight on trabecular bone in rats. Am J Physiol 244: 310-314.

38. Roberts WE, Fielder, Rosenoer LM, Maese AC, Gonsalves MR, Morey ER, 1987 Nuclear morphological analysis of osteoblast precursor cells in periodontal ligament, SL-3 rats. Am J Physiol 252: 247-251.

39. Doty SB, 1985 Morphologic and histochemical studies of bone cells from Spacelab-3 rats. Physiologist 28: 225226.

40. Garetto LP, Gonsalves MR, Morey ER, Durnova G, Roberts WE, 1990 Preosteoblast production 55 hours after a 12.5-day spaceflight on Cosmos 1887. FASEB J 4: 24-38.

41. Garetto LP, Morey ER, Durnova GN, Kaplansky A, Roberts WE, 1992 Preosteoblast production in COSMOS 2044 rats: short-term recovery of osteogenic potential. J Appl Physiol 73: 14-18.

42. Stein GS, Lian JB, 1993 Molecular mechanisms mediating proliferation/differentiation interrelationships during progressive development of the osteoblast phenotype. Endocr Rev 14: 414-441.

43. Patterson-Buckendahl PE, Grindeland RE, Martin RB, Cann CE, Arnaud CD, 1985 Osteocalcin as an indicator of bone metabolism during spaceflight. The Physiologist 28: 227-228.

44. Bikle DD, Harris J, Halloran BP, Morey-Holton ER, 1994 Altered skeletal pattern of gene expression in response to spaceflight and hindlimb elevation. Am J Physiol 267: 822-827.

45. Doty SB, Morey-Holton ER, 1998 Changes in osteoblastic activity due to simulated weightless conditions. The Physiolgist 25: 141-142.

46. Vico L, Chappard D, Alexandre C, et al, 1987 Effect of weightlessness on bone mass and osteoclast number in pregnant rats after a five-day spaceflight (Cosmos 1514). Bone 8: 95-103.

47. Wronski TJ, Morey-Holton E, Jee WSS, 1980 Cosmos 1129: space flight and bone changes. The Physiologist 23: 79-82.

48. Yagodovski VS, Triftanidi LA, Gorokhova GP, 1976 Spaceflight effects on skeletal bones of rats (light and electron microscope examinations). Aviat Space Environ Med 47: 734-738.

49. Spengler DM, Morey ER, Carter DR, Turner RT, Baylink DJ, 1983 Effects of space flight on structural and material strength of growing bone. Proc Soc Exp Biol Med 174: 224-228.

50. Shaw SR, Vailas AC, Grindeland RE, Zernicke RF, 1988 Effects of a 1-week spaceflight on morphological and mechanical properties of growing bone. Am J Physiol 254: 78-83.

51. Van Loon JJWA, Bervoets D, Burger EH, et al, 1995
Decreased mineralization and increased calcium release in isolated fetal mouse long bones under near weightlessness. J Bone Min Res 10: 550-557.

52. Vico L, Alexandre C, 1990 Bone cellular effects after weightlessness exposure. A hypothesis. Physiologist 33: 8-11.

53. LeblanK DA, Schneider E, Spector E, et al, 1995 Calcium absorption, endogenous excretion, and endocrine changes during and after long-term bed rest. Bone 16: 301-304.

54. LeblanK DA, Schneider SV, Evans JH, Engelbretson AD, Krebs MJ, 1990 Bone mineral loss and recovery after 17 weeks of bed rest. J Bone Miner Res 5: 843850.

55. Donaldson LC, Hulley BS, Vogel MJ, Hattner SR, Bayers HJ, McMillan ED, 1970 Effect of prolonged bed rest on bone mineral. Metabolism 19: 1071-1084.

56. Zerwekh JE, Ruml LA, Gottschalk F, Pak CYC, 1998 The effects of twelve weeks of bed rest on bone histology, biochemical markers of bone turnover, and calcium homeostasis in eleven normal subjects. J Bone Min Res 13: 1594-1601.

57. Grigoriev AI, Larina IM, Morukov BV 1999 Calcium metabolism characteristics in microgravity. Ross Fiziol Zh Im I M Sechenova 85: 835-846.

58. Goldsmith RS, Killian P, Ingbar SH, Bass DE, 1969 Effect of phosphate supplementation during immobilization of normal men. Metabolism 18: 349.

59. Van der Wiel HE, Lips P, Nauta J, Netelenbos JC, Hazenburg GJ, 1991 Biochemical parameters of bone turnover during ten days of bed rest and subsequent mobilization. Bone and Mineral 13: 123-129.

60. Grigoriev AI, Morukov B, Oganov VS, Rahkmanov AS, Buravkova LB, 1992 Effect of exercise and bisphosphonate on mineral balance and bone density during 360 day antiorthostatic hypokinesia. J Bone Miner Res 7: 449-455.

61. Lueken S, Arnaud CD, Taylor AK, Baylink DJ, 1990 Immobilization causes an acute sustained increase in markers of bone resorption. Clin Res 38: 990.

62. Nishimura Y, Fukuoka H, Kiriyama M, 1994 Bone turnover and calcium metabolism during 20 days bed rest in young healthy males and females. Acta Physiol Scand 616: 27-35.

63. Stewart AF, Adler M, Byers CM, Segre GV, Broadus AE, 1982 Calcium homeostasis in immobilization: an example of resorptive hypercalciuria. N Engl J Med 306: 1136-1140.

64. Lerman S, Canterbury JM, Reiss E, 1977 Parathyroid hormone and the hypercalcemia of immobilization. J Clin Endocrinol Metab 45: 425-428.

65. Vico L, Chappard D, Alexandre C, et al, 1987 Effects of a 120 day period of bed-rest on bone mass and bone cell activities in man: attempts at countermeasure. Bone and Mineral 2: 383-394.

66. Minaire P, Meunier P, Edouard C, Bernard J, Cour- 
pron P, Bourret J, 1974 Quantitative histological data on disuse osteoporosis. Calcif Tissue Res 17: 57.

67. LeBlanK AD, Schneider VS, Krebs MJ, Evans H, Jhingran S, Johnson PC, 1987 Spinal bone mineral after 5 weeks of bed rest. Calcif Tissue Int 41: 259-261.

68. Grigoriev AI, Morukov B, Oganov VS, Rahkmanov AS, Buravkova LB, 1992 Effect of exercise and bisphosphonate on mineral balance and bone density during 360 day antiorthostatic hypokinesia. J Bone Miner Res 7: 449-455.

69. Arnaud SB, Sherrard DJ, Maloney N, 1992 Effects of 1-week head-down tilt bed rest on bone formation and the calcium endocrine system. Aviat Space Environ Med 63: 14-20.

70. Brendon Noble, 2003 Bone microdamage and cell apoptosis. Eur Cells Mater 6: 46-56.

71. Verbogt O, Gibson GJ, Schaffler MB, 2000 Loss of osteocyte integrity in association with microdamage and bone remodeling after fatigue in vivo. J Bone Miner Res 15: 60-67.

72. Dauty M, Perrouin Verbe B, Maugars Y, Dubois C, Mathe JF, 2000 Supralesional and sublesional bone mineral density in spinal cord-injured patients. Bone 27: 305-309.

73. del Puente A, Pappone N, Mandes MG, Mantova D, Scarpa R, Oriente P, 1996 Determinants of bone mineral density in immobilization: A study on hemiplegic patients. Osteoporosis Int 6: 50-54.

74. Garland DE, Stewart CA, Adkins RH, 1992 Osteoporosis after spinal cord injury. J Orthop Res 10: 371-378.

75. Uebelhart CD, Hartmann D, Vuagnat H, Castanier M, Hachen H, Chantraine A, 1994 Early modifications of biochemical markers of bone metabolism in spinal cord injury patients. A preliminary study. Scand J Rehab Med 26: 197-202.

76. Keating JF, Kerr M, Delargy M, 1992 Minimal trauma causing fractures in patients with spinal cord injury. Disab Rehabil 14: 108-109.

77. Sobel M, Lyden JP, 1991 Long bone fracture in a spinal-cord-injured patient: complication of treatment-a case report and review of the literature. J Trauma 31: 1440-1444.

78. Morey-Holton ER, Bomalaski MS, Enayati-Gordon E, Gonsalves MR, Wronski TJ, 1982 Is suppression of bone formation during simulated weightlessness related to glucocorticoid levels? Physiologist 25: 145.

79. Globus RK, Bikle DD, Morey-Holton E, 1984 Effects of simulated weightlessness on bone mineral metabolism. Endocrinology 114: 2264-2270.

80. Wronski TJ, Morey-Holton E, 1987 Skeletal response to stimulated weightlessness: a comparison of suspension techniques. Aviat Space Environ Med 58: 63-68.

81. Villa G, Monteleone D, Marra C, et al, 1993 Neuropsychological abnormalities in AIDS and asymptomatic HIV seropositive patients. J Neurol Neurosurg Psychiatry 56 : $878-884$.
82. Morey-Holton ER, Globus RK, 1998 Hindlimb unloading of growing rats: a model for predicting skeletal changes during space flight. Bone 22: 83-88.

83. Hargens AR, Steskal J, Johansson C, Tipton CM, 1984 Tissue fluid shift, forelimb loading, and tail tension in tail-suspended rats. Physiologist 27: 37-38.

84. Roer RD, Dillaman RM, 1990 Bone growth and calcium balance during simulated weightlessness in the rat. J Appl Physiol 68: 13-20.

85. Bikle DD, Harris J, Halloran BP, 1995 The molecular response of bone to growth hormone during skeletal unloading: regional differences. Endocrinology 136: 2099-2109.

86. Halloran BP, Bikle DD, Wronski TJ, Globus RK, Levens MJ, Morey-Holton E, 1986 The role of 1,25-dihydroxyvitamin $\mathrm{D}$ in the inhibition of bone formation induced by skeletal unloading. Endocrinology 118: 948954.

87. Patterson-Buckendahl PE, Globus RK, Bikle DD, Cann CE, Morey-Holton E, 1989 Effects of simulated weightlessness on rat osteocalcin and bone calcium. Am J Physiol 257: 1103-1109.

88. Globus RK, Bikle DD, Morey-Holton E, 1986 The temporal response of bone to unloading. Endocrinology 118: 733-742.

89. Bikle DD, Halloran BP, Cone CM, Globus RK, Morey-Holton E, 1987 The effects of simulated weightlessness on bone maturation. Endocrinology 120: 678684.

90. Machwate M, Zerath E, Holy X, et al, 1993 Skeletal unloading in rat decreases proliferation of rat bone and marrow-derived osteoblastic cells. Am J Physiol 264: 790-799.

91. Abram AC, Keller TS, Spengler DM, 1988 The effects of simulated weightlessness on bone biomechanical and biochemical properties in the maturing rat. J Biomech 755-767.

92. Halloran BP, Bikle DD, Harris J, Foskett HC, MoreyHolton E, 1993 Skeletal unloading decreases production of 1,25-dihydroxyvitamin D. Am J Physiol 264: 712716.

93. Sessions NDV, Halloran BP, Bikle DD, Wronski TJ, Cone CM, Morey-Holton E, 1989 Bone response to normal weight bearing after a period of skeletal unloading. Am J Physiol 257: 606-610.

94. Silbermann M, Bar-Shira-Maymon B, Coleman R, et al, 1990 Long-term physical exercise retards trabecular bone loss in lumbar vertebrae of aging female mice. Calcif Tissue Int 46: 80-93.

95. Pate RR, Pratt M, Blair SN, et al, 1995 Physical activity and public health: A recommendation from the Centers for Disease Control and Prevention and the American College of Sports Medicine. JAMA 237: 402407.

96. Nichols DL, Sanborn CF, Bonnik SL, Ben-Ezra V, Gench B, DiMarco NM, 1994 The effects of gymnas- 
tics training on bone mineral density. Med Sci Sports Exerc 26: 1220-1225.

97. Dalsky GP, Stocke KS, Ehsani AA, Slatopolsky E, Lee WC, Birge SJ, 1988 Weight-bearing exercise training and lumbar bone mineral content in postmenopausal women. Ann Intern Med 108: 824-828.

98. Uuri-Rasi K, Sievanen H, Vuori I, Pasanen M, Heinonen A, Oja P 1998 Association of physical activity and calcium intake with bone mass and size in healthy women at different ages. J Bone Miner Res 13: 133-142.

99. Ziambaras K, Lecanda F, Steinberg TH, Civitelli R, 1998 Cyclic stretch enhances gap junctional communi- cation between osteoblastic cells. J Bone Miner Res 13: 218-228.

100. Civitelli R, Ziambaras K, Warlow PW, et al, 1998 Regulation of Connexin43 expression and function by prostaglandin E2 (PGE2) and parathyroid hormone (PTH) in osteoblastic cells. J Cell Biochem 68: 8-21.

101. Frost H 1999 Musculoskeletal System Interactions. A brief overview, with insights from the Utah Paradigm of Skeletal Physiology. In: Musculoskeletal Interactions, Basic and Clinical aspects, Lyritis GP, (eds) Hylonome editions, 2: 25-34. 